\title{
Cultural influences on students' perceptions of videotaped lessons
}

\author{
Perry den Brok ${ }^{\mathrm{a}, *}$, Jack Levy ${ }^{\mathrm{b}}$, Theo Wubbels ${ }^{\mathrm{c}}$, \\ Marvin Rodriguez ${ }^{\mathrm{d}}$ \\ ${ }^{a}$ IVLOS, Institute of Education, Utrecht University, P. O. Box 80.127, 3508 TC Utrecht, The Netherlands \\ ${ }^{\mathrm{b}}$ Graduate School of Education, George Mason University, Fairfax, VA, USA \\ ${ }^{\mathrm{c}}$ Department of Educational Sciences, Utrecht University, Utrecht, The Netherlands \\ ${ }^{\mathrm{d}}$ Fauquier County Schools, Fauquier County, VA, USA
}

\begin{abstract}
This study investigated the effect of students' cultural background on their perceptions of videotaped teacher behavior. Earlier research was not able to determine if behaviors perceived differently by students from various cultural groups were caused by dissimilar teacher treatment or differences with respect to students' norms, values, and needs. By keeping teacher behavior constant, further evidence was sought for the second of these two possible causes. Seventy-eight students in four cultural groups (Asian-American, Hispanic-American, AfricanAmerican and White-American) watched four video lesson segments and completed a questionnaire on interpersonal teacher behavior. Asian-American students felt the teachers displayed more uncertainty than their peers from other ethnic groups, while students mainly speaking Spanish at home perceived more helpful, friendly and understanding behavior. The outcomes provide further support for the assumption that students' perceptions are influenced by their cultural background.
\end{abstract}

(C) 2003 Elsevier Science Ltd. All rights reserved.

Keywords: Student perception; Interpersonal behavior; Teacher-student relationship; Ethnicity; Multicultural classes

\section{Rationale}

As a result of the extremely diverse school population in the US, educators are continually attempting to understand the role played by

*Corresponding author. Tel.: + 31-30-2532231; fax: +31-30-2532741.

E-mail address: p.denbrok@ivlos.uu.nl (P.den Brok). 
culture $^{1}$ in student performance. Comprehending culturally influenced motivations and perceptions is a complex task, since culture is all-pervasive, multidimensional and dynamic. Cultural characteristics can be shared by a group of people as a whole or by several of its subgroups, and might consist of various languages, values, traditions, religions, and beliefs that are sure to change over time (i.e., from one generation to another, or as a result of migration patterns, geopolitical boundary developments, etc.). Because of their complicated nature, it is unclear which cultural factors are important in the learning process and to what extent they are subject to change.

There is undoubtedly a relationship between cultural membership, students' interpretations of their learning environment, and the way their teachers communicate. Teaching and learning require perception and communication, both of which are culturally influenced (Au \& Kawakami, 1994; Grossman, 1995; Nieto, 1996; Matsuda, 1989; Nguyen, 1984; Samovar \& Porter, 1995; Stefani, 1997, among many others). Cultures differ in the type of information perceived, stored and used (Sturtevant, 1964; Witkin, 1967; Cole \& Scribner, 1974; Segall, Dasen, Berry, \& Poortinga, 1990). As a result, an extensive literature on cultural differences in cognition, conceptualization and knowledge construction has accumulated and can only be discussed to a limited extent in this paper (for a review, see Gordon, 1995). Culture's role in influencing students' perceptions is also a continuing research theme, with numerous books and journals devoted to it.

Following this line of inquiry, research conducted by the authors and others has found that student perceptions of their teachers differ according to the cultural membership of both students and teachers, among many other variables (den Brok, Levy, Rodriguez, \& Wubbels, 2002; Levy, den Brok, Wubbels, \& Brekelmans, 2003; Evans \& Fisher, 2000; Levy, Wubbels, Brekelmans, \& Morganfield, 1997; Fisher, Rickards, Goh, \& Wong, 1997; Levy, Wubbels, \& Brekelmans, 1996; McCroskey, Richmond, Sallinen, Fayer, \& Barraclough, 1995; Neuliep, 1995; Sanders \& Wiseman, 1990). The associations between student perceptions and student and teacher cultural membership can be explained in various ways. One plausible argument is that teachers treat students from different ethnic backgrounds differently, and that this results in variations in students' perceptions. Evidence for this explanation was provided by a series of observation studies conducted in the 1980s and 1990s (e.g. Simpson \& Erickson, 1983; Irvine, 1985, 1986; Casteel, 1996).

\footnotetext{
${ }^{1}$ In this study, the term "culture" and "ethnicity" are both used. Following Nieto (1996, p. 390), we define culture as "the ever-changing values, traditions, social and political relationships, and worldview created and shared by a group of people bound together by a combination of factors (which can include a common history, geographic location, language, social class, and/or religion), and how these are transformed by those who share them'. We use ethnicity to refer to 'foreign or native population groups' (Pinto, 2000, p. 9). As such, ethnicity can be regarded as one of the indicators that binds people, thus as one of the many elements that make up culture.

While not uncommon in the research, the categories used to describe the cultural and ethnic groups mentioned in this paper-African-American, Hispanic, Hispanic-American, Asian, Asian-American, White - do not indicate the enormous diversity within groups. This will be further explained in later sections, as well as described in the paper's limitations.
} 
Another explanation is that students perceive the same teacher behavior differently. Accordingly, such variations in perception are the result of differences in interpretation, values, norms, or needs of the students, all influenced by ethnicity. An example can be seen in a recent study by den Brok (2001), who demonstrated a systematic bias in students' perceptions, related to needs and norms for structured support, rejection and autonomy. While evidence supports both explanations, very little research has been conducted which tries to isolate one or the other. Most studies have been conducted in natural settings in which different students in different classes perceived different teachers. As a result, both explanations may be valid, and no arguments can be made regarding their relative importance. The present study, in which students from different ethnic backgrounds were shown four videotaped lesson segments, attempted to support the second line of reasoning by keeping teacher behavior and characteristics constant for all students.

\section{Interpersonal teacher behavior}

The Model for Interpersonal Teacher Behavior (MIB) is based on Timothy Leary's (1957) research on the interpersonal diagnosis of personality and its application to teaching (Wubbels, Créton, \& Hooymayers, 1985, 1987). The Leary model has been investigated extensively and proven effective in describing human interaction (Foa, 1961; Lonner, 1980). While not conclusive, there is evidence that the Leary model is cross-culturally generalizable (Brown, 1965; Dunkin \& Biddle, 1974; Lonner, 1980; Segall et al., 1990).

The model describes interpersonal teacher behavior (sometimes called communication style) along two dimensions: influence (DS, or dominance-submission), and proximity ( $\mathrm{CO}$, cooperation-opposition). The influence dimension represents the degree of control or dominance displayed by the teacher, while proximity describes the level of cooperation or opposition between teacher and students. These two dimensions can be represented in a coordinate system divided into eight equal sectors (see Fig. 1). The sectors are labelled DC, CD, and so on, according to their position on the graph. For example, both the sectors DC and CD are both characterized by dominance and cooperation. However, the DC sector demonstrates a higher degree of dominant behaviors than cooperation. Similarly, the adjacent sector CD includes actions that are more cooperative and less dominant. Each of the eight sectors describes different teacher behaviors: leadership, helpful/friendly, understanding, student responsibility and freedom, uncertain, dissatisfied, admonishing and strict.

\section{The questionnaire on teacher interaction}

Data on teacher communication style can be gathered with the Questionnaire on Teacher Interaction (QTI, Wubbels et al., 1985; Wubbels \& Levy, 1991). The QTI was originally developed in the Netherlands, and a 64-item American version was constructed in 1988. A recent review on the validity and reliability of over 20 studies 


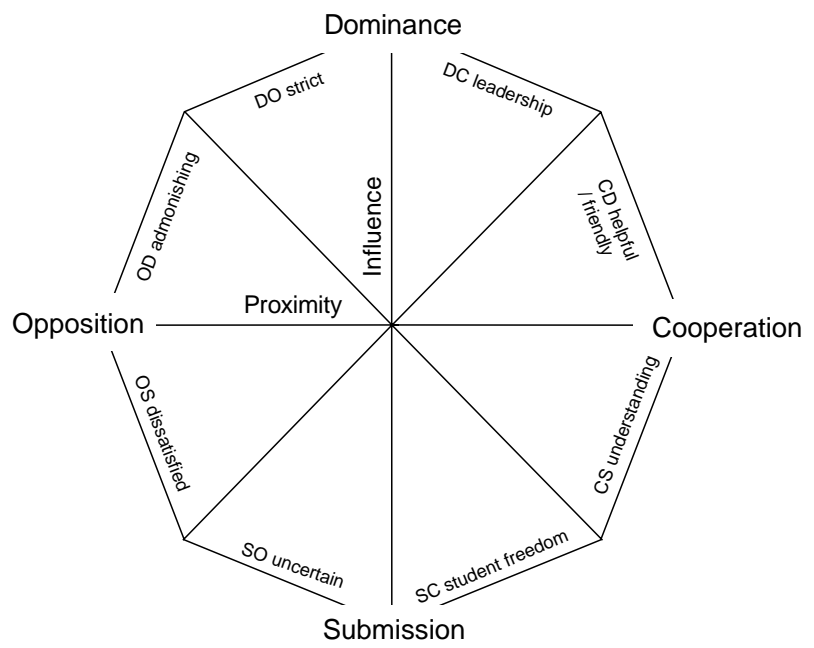

Fig. 1. The model for interpersonal teacher behavior.

that have used the QTI during the last two decades (den Brok, 2001) showed that reliability coefficients of the eight scales or sectors are generally above 0.80 - while a value of 0.70 (Nunally, 1967) is considered sufficient for research purposes - and consistent across classes. Moreover, the review showed that the circular structure (often referred to as circumplex) of the interpersonal model was sufficiently represented in the items and scales of the instrument.

The QTI has eight behavior scales, from DC (leadership) to DO (strictness). It employs a five-point response range, from "never/not at all" to "always/very". Scoring is based on the eight sectors and two dimensions, or summarizing factors (influence (DS) and proximity (CO)). While both dimensions are based on all of the sectors, behaviors in the sectors closest to the DS axis - strictness, leadership, student responsibility/freedom, and uncertainty - are most important for the influence dimension; while helpful/friendly, understanding, dissatisfied and admonishing behavior are most relevant to the proximity dimension. High ratings on the influence dimension have been correlated positively with cognitive student achievement. Correspondingly, high proximity scores relate positively to affective outcomes (e.g. attitudes) (Brekelmans, Wubbels, \& Creton, 1990; Brekelmans, van den Eeden, Terwel, \& Wubbels, 1997; den Brok, 2001).

\section{Cultural differences in students' perceptions of teachers' interpersonal behavior}

A number of studies have investigated the effects of cultural factors on students' perceptions of their teachers' interpersonal behavior. This research has included a number of ethnic variables such as self-designated ethnicity, country of birth, the 
numbers of years students have been living in the country of interest, and language spoken at home.

Studies conducted in US multicultural classes reported that Asian-American students viewed their teachers as less dominant and cooperative than students from other ethnic groups, and that Asian-American teachers were seen to be less dominant and cooperative by students than their Hispanic-American, African-American or Caucasian colleagues (den Brok et al., 2002; Levy et al., 1996, 2003). In these studies, Hispanic-American students usually perceived the most dominance and cooperation and Hispanic-American teachers were rated highest on teacher influence and proximity. In one US study, primary home language, rather than self-designated ethnic membership, was significant: students speaking mainly English at home perceived the least dominance, and classes with the most predominantly Englishspeaking students perceived the least dominance of all groups (Levy et al., 1997). Another study found a significant effect for the number of years students had been living in the US: the longer they lived there, the less dominance they perceived (Levy et al., 2003).

In contrast to the US results cited above, a few studies on the same topic have been initiated in Australia and the Pacific. An Australian study by Evans and Fisher (2000) found that students born in South Africa perceived more strictness and less uncertainty than their Australian counterparts, while Asian-born students felt their teachers were less uncertain (e.g. more sure of themselves) than did their SouthAfrican-born classmates. Similarly, in a cross-national study, it was found that students in Singapore perceived less student responsibility and freedom and more strictness than Australian students (Fisher et al., 1997). Naturally, context (the country of interest) helps explain the differences in the results.

Researchers have interpreted these outcomes in terms of cultural dimensions that are often used to explain differences across groups, such as those put forth by Hofstede, Hall, Triandis and others (see den Brok et al., 2002). For example, relatively high proximity ratings found for Hispanic-American students and correspondingly low scores found for White students have partially been explained in terms of collectivism-individualism and approach-avoidance (den Brok et al., 2002; Levy et al., 2003). In a similar manner, the tendency of Asian-Americans and Hispanic-Americans to perceive a great amount of teacher-centered, dominant behavior has been interpreted according to Hofstede's dimension of power distance or approach to authority (Hofstede, 1991).

The literature suggests that North-American and West-European cultures can be regarded as relatively individualistic, while Latin American and Asian cultures are more group-oriented. In collectivistic cultures, behaviors which correspond to immediacy or proximity seem to be more prevalent (Hofstede, 1991; Sanders, Gass, Wiseman, \& Bruschke, 1992; McCroskey et al., 1995), and this contributes to the greater identification of Hispanic-American students of this factor over their White peers. The stronger perceptions of Hispanic-American students can also be explained in the reverse: these students may expect teachers to be cooperative and therefore regard behaviors that reflect this as 'normal', and, as a consequence, automatically rate their teachers high on proximity. 
In a number of studies, students felt that their Asian-American teachers were not as cooperative (e.g. they were rated low on proximity) as others (den Brok et al., 2002; Levy et al., 1996). One possible explanation can be derived from an analysis of the approach-avoidance cultural dimension. The literature suggests that Asian cultures prefer communication that is indirect and that they tend to take a humble position towards the other communication partner (e.g. Lu, 1997; Liberman, 1994). In addition, the instructor in Asian countries assumes a more dominant, distant role in class, in contrast to his/her American counterparts (Lu, 1997; Chinese Culture Connection, 1987). Moreover, in countries in Asia or Latin America which exhibit a great deal of power distance-where large differences in power exist in the populace and, consequently, between teachers and students - teachers are expected to exert a significant amount of influence over their students. When students originating from these countries experienced (in this case) American or Australian teachers who engaged in discussions and allowed for independent, self-directed activities, it seems logical that they may interpret this as weakness resulting in relatively low ratings for leadership and high for uncertainty.

Clearly, the concept of culture is so complex that these cultural dimensions only have limited value in interpreting the outcomes. Moreover, results have not been consistent throughout the cited research, which raises questions about generalizability. Finally, as noted in footnote 1, it is obvious that there is enormous diversity within groups and interpretations based on broad dimensions may not explain individual perceptions. In a complicated field, prior research can only be regarded as preliminary and each study provides incremental clues.

\section{Research question}

The following research question was investigated: Is there a difference in students' perceptions of videotaped interpersonal teacher behavior according to their birthplace and ethnic group membership? Addressing this question allowed us to investigate the nature of cultural differences in perceptions when teacher behavior and characteristics were kept constant for all students.

\section{Design}

\subsection{Sample}

Data were gathered on 78 secondary-school students from four ethnic groups who attend three Washington, DC metropolitan area secondary schools. Students and teachers in the study identified themselves in four broad categories: White, AfricanAmerican, Hispanic-American and Asian-American (see footnote 1). When reporting on the ethnic group membership of the teachers and students, the terms "Hispanic", "Latino", "Hispanic-American", “Asian-American", "Asian", "Black", "African-American" and "White" are used to label the categories. As 
mentioned, it is clear that these labels can be misleading, since a tremendous amount of diversity exists within each category. The researchers selected one student from each ethnic group and asked him/her to name other members of that culture (convenience sample) until a full complement was achieved. Students received a small stipend for their participation.

Of the 78 participating students, 19 identified themselves as African-American, 16 Asian-American, 22 Hispanic-American and 21 White. A total of 54 or $69.2 \%$ of the students were born in the United States or lived here for more than 10 years. A great majority of the students predominantly spoke English at home (59 or $75.6 \%$ ). Thus, while they described themselves as members of subcultures, most of the students had probably been socialized into mainstream American culture to a large degree. The students were between 15 and 18 years of age and attended grades 9-12. The sample consisted of 38 girls $(48.7 \%)$ and 40 boys.

The four teachers were each from a different cultural group-African-American, Asian-American, Hispanic-American and White-American-and consisted of three females and one male. The teachers were in their mid-20s and mid-30s.

\subsection{Procedure}

As mentioned, this study attempted to control for teaching and teacher variables by ensuring that students from different ethnic groups observed the exact same behavior. Four teachers volunteered to participate in the study and were videotaped conducting different geometry lessons. A 15-min segment was chosen for each teacher based on the variety of behaviors displayed. Each segment included both teacher instruction as well as student participation, and an attempt was made to include as many of the eight QTI categories as possible.

In the four non-randomized groups of approximately 10 students each, mixed in terms of self-defined ethnic group membership, students were shown all four video segments. In the groups video segments were shown in a randomised order. After watching each tape participants completed a 40-item, modified version of the Questionnaire on Teacher Interaction (QTI) (see description below) and answered questions on age, gender, grade and ethnic background. With respect to ethnic background, students were asked to indicate their country of birth, the number of years they had been living in the US, and the language spoken at home most of the time.

\subsection{Instrumentation}

In the interest of time, it was decided not to use the original 64-item QTI, but a modified 40-item version (see Appendix A). The modified instrument contained five items for each of the sectors in the model. Items were selected because of their high internal consistency in past studies with American high school students.

To assess reliability and validity of the modified QTI, a reliability analysis on each of the eight scales was conducted. Table 1 lists the reliabilities for each scale. Interestingly, the CD (helpful/friendly) and CS (understanding) scales did not 
Table 1

Number of items and alpha-reliability coefficients for the QTI scales

\begin{tabular}{|c|c|c|c|c|}
\hline \multirow[t]{2}{*}{ Scale } & \multirow[t]{2}{*}{ Typical item } & \multicolumn{3}{|c|}{ Reliability } \\
\hline & & Items & $\begin{array}{l}\text { Revised 37-item } \\
\text { version }\end{array}$ & $\begin{array}{l}\text { Prediction for } \\
64 \text {-item version }\end{array}$ \\
\hline DC-leadership & $\mathrm{S} /$ he is a good leader & 5 & 0.85 & 0.87 \\
\hline CD - helpful/friendly & $\begin{array}{l}\mathrm{S} / \text { he is someone we can } \\
\text { depend on }\end{array}$ & 4 & 0.68 & 0.81 \\
\hline CS - understanding & $\begin{array}{l}\text { If we have something to } \\
\text { say s/he will listen }\end{array}$ & 3 & 0.68 & 0.85 \\
\hline $\begin{array}{l}\mathrm{SC} \text {-student } \\
\text { responsibility/freedom }\end{array}$ & $\begin{array}{l}\mathrm{S} / \text { he gives us a lot of free } \\
\text { time in class }\end{array}$ & 5 & 0.75 & 0.83 \\
\hline $\mathrm{SO}$-uncertain & $\mathrm{S} /$ he seems uncertain & 5 & 0.81 & 0.86 \\
\hline OS - dissatisfied & $\mathrm{S} /$ he is suspicious & 5 & 0.71 & 0.82 \\
\hline OD_admonishing & $\mathrm{S} /$ he gets angry & 5 & 0.75 & 0.83 \\
\hline DO_-strict & $\mathrm{S} /$ he is strict & 5 & 0.71 & 0.82 \\
\hline
\end{tabular}

demonstrate enough internal reliability due to three items which did not fit into their original scales. After the items were deleted, both reliability and factor structure improved (the items are indicated with a \# in Appendix A). However, the reliability coefficient alpha of the CD and CS scales failed to reach the 0.70 limit, which is considered to be acceptable for research purposes (Nunally, 1967). These lowreliability coefficients might have been caused by the fact that the modified QTI had one-third fewer items than the original instrument. We therefore also computed a predicted reliability, estimating the coefficients as though the original QTI had been used. $^{2}$ All of the predicted reliabilities (see Table 1) were above 0.80 , providing enough confidence to proceed with the selected set of items.

To assess intercultural validity of the modified QTI, separate analyses were performed on the data of each of the four ethnic membership groups (AfricanAmericans, Asian-Americans, Hispanic-Americans and Caucasian or White Americans). For each group correlations between the eight sectors of the model were computed. The resulting correlation matrices can be found in Appendix B.

Each correlation matrix was subjected to a correspondence analysis (Hubert \& Arabie, 1987; Tracey, 1997) to test circumplexity of the data (e.g. to test if sectors are ordered in terms of a circle with two underlying, independent dimensions). If a circumplex structure - such as the model of interpersonal teacher behavior is assumed to be - can be found, correlations between neighbouring scales or sectors should be high and positive. They should decrease with scales or sectors that are more distant in the interpersonal circle, with high and negative correlations between opposite sectors. In a correspondence analysis, these correlational assumptions are

\footnotetext{
${ }^{2}$ The Spearman-Brown formula for test length was used. According to this formula$$
\rho_{\text {new }}=\sqrt{ }\left(K / K \rho_{\text {old }}+1-\rho_{\text {old }}\right),
$$

where $\rho$ is the reliability coefficient alpha and $K$ designates how much longer the test has become.
} 
tested, and the degree to which they have been met are reported in terms of a correspondence index $(\mathrm{CI})$, that is accompanied by a probability estimate. The CI can range between 0 and 1 , with values close to 1 indicating a circumplex structure. A value of 0.5 indicates that many more assumptions are confirmed $(75 \%)$ than rejected (25\%) (see Tracey, 1994). In a study by Tracey and Schneider (1995) CI values of 0.80 were reported as 'very high', while the same study showed CI values between 0.35 and 1. An earlier study (Tracey, 1994) described CI values between 0 and 0.40 as 'moderate'. CIs and their probabilities were computed with the RANDALL software package (Tracey, 1997). A CI of $0.90(p=0.0004)$ was found for the African-American group, while the CI was $0.99(p=0.0001)$ for the AsianAmerican matrix, $0.87(p=0.0004)$ for the Hispanic-American matrix, and 0.85 $(p=0.0005)$ for the White student perception correlation matrix. These values indicate a circumplex structure for each of the groups, and show that validity is only affected to a small degree by ethnic group membership, since variation in the CIs is limited.

As a further check of validity - since correspondence analyses are rather rough measures of circumplexity - and to test equality of structure of the correlation matrices of Appendix B, confirmatory factor analyses were performed for each ethnic membership group, testing different circumplex factor models. This was done with the MPLUS software (Muthén \& Muthén, 2001), using multiple group analysis. Three circumplex models were tested: a perfect circumplex (assuming an equally spaced, circular, two-dimensional factor structure ${ }^{3}$ ), a quasi-circumplex (assuming a symmetrical, circular, but not equally spaced, two-dimensional factor structure) and an irregular circumplex (testing a two-dimensional factor structure with free factor loadings) (see Gaines et al. (1997) for details). In all models, no correlation was allowed between the two dimensions (DS and CO). Two sets of analyses were conducted, one specifying the same factor loadings in all four ethnic membership groups, the second specifying different factor loadings (under a similar factor structure) for each group. Table 2 presents model fit estimates for each of the analyses.

As can be seen in Table 2, none of the analyses shows a perfect fit, while all show moderate to considerate distance between models and data. ${ }^{4}$ The best fit is shown for the analysis testing the irregular circumplex and allowing for different factor

\footnotetext{
${ }^{3}$ In an ideal circumplex, factor loadings of the two dimensions (or factors) follow a predetermined pattern, based on their angular location in the circumplex. In those models dimension scores are computed as follows:

$$
\begin{aligned}
\text { Influence }= & (0.92 * \mathrm{DC})+(0.38 * \mathrm{CD})-(0.38 * \mathrm{CS})-(0.92 * \mathrm{SC}) \\
& -(0.92 * \mathrm{SO})-(0.38 * \mathrm{OS})+(0.38 * \mathrm{OD})+(0.92 * \mathrm{DO}), \\
\text { Proximity }= & (0.38 * \mathrm{DC})+(0.92 * \mathrm{CD})+(0.92 * \mathrm{CS})+(0.38 * \mathrm{SC}) \\
& -(0.38 * \mathrm{SO})-(0.92 * \mathrm{OS})-(0.92 * \mathrm{OD})-(0.38 * \mathrm{DO}) .
\end{aligned}
$$

These scores range between about -3 and +3 .

${ }^{4}$ For adequate model fit Chi-squared values should not be significant, CFI and TLI values should be above 0.90, while SRMR should stay below 0.05 (e.g. Hox, 1995).
} 
Table 2

Model fit indicators of confirmatory factor analyses on scale correlation matrices of the four ethnic groups

\begin{tabular}{lllll}
\hline Model & $\chi^{2} / \mathrm{df} / p$-value & CFI & TLI & SRMR \\
\hline Ideal circumplex - same loadings per group & $404.92 / 100 / 0.00$ & 0.80 & 0.77 & 0.14 \\
Quasi-circumplex - same loadings per group & $357.94 / 97 / 0.00$ & 0.83 & 0.80 & 0.17 \\
Quasi-circumplex - different loadings per group & $334.06 / 76 / 0.00$ & 0.83 & 0.75 & 0.16 \\
Irregular circumplex - same loadings per group & $257.27 / 112 / 0.00$ & 0.89 & 0.86 & 0.10 \\
Irregular circumplex-different loadings per group & $205.83 / 52 / 0.00$ & 0.90 & 0.78 & 0.05 \\
\hline
\end{tabular}

loadings for each of the groups. Analyses testing the irregular circumplex structure separately on each of the four groups showed adequate model fit for the White American $\left(\chi^{2}=29.80 / p=0.005 ; \mathrm{CFI}=0.96 ; \mathrm{TLI}=0.92\right.$ and $\left.\mathrm{SRMR}=0.03\right)$ and Asian-American groups $\left(\chi^{2}=47.48 / p=0.00 ; \mathrm{CFI}=0.90 ; \mathrm{TLI}=0.77\right.$ and $\mathrm{SRMR}=$ $0.05)$, but weaker model fit for the African-American $\left(\chi^{2}=50.04 / p=0.00\right.$; $\mathrm{CFI}=0.87$; TLI $=0.72$ and SRMR $=0.05)$ and Hispanic-American $\left(\chi^{2}=78.50 / p=\right.$ $0.00 ; \mathrm{CFI}=0.85 ; \mathrm{TLI}=0.68$ and $\mathrm{SRMR}=0.06)$ groups. This means that the circumplex model for interpersonal teacher behavior and its dimension scores (DS and $\mathrm{CO}$ ) are not equally supported in each of the ethnic groups. Because of these irregularities, subsequent analyses have only been carried out for the sector scores and not for dimension scores (the latter were assumed to underlie the data, but their cross-cultural validity was only supported by the correspondence analyses).

\subsection{Analyses}

To determine the influence of student's cultural background, analyses of variance (MANOVA) were performed on the eight sectors. Two sets of analyses were performed: one estimating the 'raw effects' of ethnicity, the other estimating 'adjusted effects' by controlling for biasing student characteristics. The first set of analyses used the sector scores as the dependent variables and the ethnicity variables (ethnic group membership, language spoken at home and number of years in the US) as the independent, with no student covariates. The second set of analyses was similar to the first, but included student gender, age and report card grade as covariates. These covariates were introduced because earlier studies showed they were strongly related to student perceptions of teacher interpersonal behavior and that their effect displayed overlap with that of student ethnicity variables (Levy et al., in press). Also, since only four teachers participated in the study and all students rated these teachers, almost all teacher variables, such as gender, experience or ethnic background, had complete overlap with and could not be disentangled from the teacher identification number variable. Therefore, teacher identification number was entered as a covariate in the analyses (as a categorical variable, represented by a set of dummies). Interaction effects between the ethnicity variables were also tested. Scheffé-tests for post-hoc comparisons of differences were performed to check if these differences were significant (Hays, 1973). Because of the homogeneity of the 
sample, the number-of-years-in-the-US category was recoded into a binary variable, indicating whether students were born in the US or not.

\section{Results}

As mentioned in the introductory section, research has demonstrated that selfdesignated ethnic membership of students related significantly to their perceptions of teacher interpersonal behavior. The present study resulted in similar outcomes, in that there were some significant differences in a number of variables related to culture. However, the outcomes of the study should be regarded as tentative, because the small sample used cannot rule out the possibility of that results occurred 'by chance'. Also, because of the small sample, a number of empty cells were found. Further research will be necessary to confirm the findings that will be reported here.

Table 3 reports the significance of the ethnic membership variables for the two sets of analyses. As can be seen from Table 3, most of the ethnic variables are not related to students' perceptions of videotaped teacher interpersonal behavior (when students are shown the same teacher behavior on videotape). Also, it can be seen that the differences in outcomes between the 'raw' and 'adjusted' analyses are small, indicating a separate and independent effect of ethnicity variables on students' perceptions. In the next section, we will discuss significant findings more in detail.

First, students' language spoken at home was related to students' perceptions of the video teachers' "understanding" behaviors: a significant difference was found between the students that spoke mainly Spanish at home and students speaking Asian languages or English at home $(F=3.42)$. The former group of students perceived more Understanding than their peers (see Table 4).

While significant, language spoken at home only explained $3 \%$ of the total variance in the understanding category. In terms of the variance explained by the variables entered in the analysis, however, language accounted for $65 \%$ of the explained variance.

Table 3

MANOVA outcomes for sector scores of the QTI ( $F$ values) with raw and adjusted effects of ethnic variables

\begin{tabular}{|c|c|c|c|c|c|c|c|c|c|c|c|c|c|c|c|}
\hline & \multicolumn{2}{|l|}{$\mathrm{DC}$} & \multicolumn{2}{|l|}{$\mathrm{CD}$} & \multicolumn{2}{|l|}{$\mathrm{CS}$} & \multicolumn{2}{|l|}{$\mathrm{SC}$} & \multicolumn{2}{|l|}{ SO } & \multicolumn{2}{|l|}{ OS } & \multicolumn{2}{|l|}{ OD } & DO \\
\hline & Raw & Adj. & Raw & Adj. & Raw & Adj. & Raw & Adj. & Raw & Adj. & Raw & Adj. & Raw & Adj. & Raw Adj. \\
\hline & & 0.71 & 0. & 0.58 & 1 & 1.22 & 53 & 0.69 & 1.29 & 1.19 & 1.96 & 1.69 & $2.80^{*}$ & 3.18 & $.02 \quad 0.16$ \\
\hline Lang & 3 & 1.94 & 1.32 & 1.24 & $3.42 *$ & $2.86^{*}$ & 1.58 & 1.09 & 0.81 & 0.46 & 8 & 1.62 & 1.16 & 1.02 & . $.09 \quad 1$. \\
\hline US & 2.98 & 2.73 & 1.86 & 1.58 & $3.94 *$ & 2.79 & 1.34 & 1.79 & 0.36 & 0.34 & $7.33^{*}$ & $6.70^{*}$ & 3.77 & $4.36^{*}$ & 0.190 .06 \\
\hline $\begin{array}{l}\text { Lang* years } \\
\text { in US }\end{array}$ & 3.29 & 2.80 & 1.61 & 1.43 & $6.79 *$ & $6.18^{*}$ & 1.20 & 1.48 & 0.27 & 0.34 & $9.22 *$ & $9.77^{*}$ & 3.61 & $4.26^{*}$ & $0.30 \quad 0.07$ \\
\hline Ethn $*$ Lang & 3.22 & 1.73 & 1.28 & 0.95 & $4.57^{*}$ & $4.38 *$ & 0.49 & 0.65 & 0.04 & 0.00 & 1.58 & 2.32 & 0.20 & 0.49 & $\begin{array}{ll}0.15 & 0.07\end{array}$ \\
\hline
\end{tabular}

*Significant at 0.05 .

Raw: no correction for covariates; adj.: correction for student age, gender and report card grade. 
Table 4

Means and standard deviations (within brackets) for understanding, dissatisfied and admonishing by language spoken at home and number of years lived in the US

\begin{tabular}{lllll}
\hline Years in the US & Language & Understanding (CS) & Dissatisfied (OS) & Admonishing (OD) \\
\hline Born in US & English & $0.68(0.21)$ & $0.19(0.17)$ & $0.18(0.20)$ \\
& Spanish & $0.83(0.15)$ & $0.04(0.07)$ & $0.09(0.09)$ \\
& Asian & Not available & Not available & Not available \\
& Other & Not available & Not available & Not available \\
Not born in US & English & $0.71(0.19)$ & & \\
& Spanish & $0.77(0.21)$ & $0.19(0.16)$ & $0.17(0.18)$ \\
& Asian & $0.70(0.24)$ & $0.21(0.16)$ & $0.14(0.13)$ \\
& Other & $0.63(0.15)$ & $0.26(0.16)$ & $0.18(0.25)$ \\
& & & $0.30(0.16)$ & $0.23(0.17)$ \\
\hline
\end{tabular}

Table 5

Means and standard deviations (within brackets) for admonishing by ethnic membership

\begin{tabular}{lc}
\hline Ethnic membership & Admonishing (OD) \\
\hline African-American & $0.16(0.17)$ \\
Asian-American & $0.19(0.22)$ \\
Hispanic-American & $0.14(0.15)$ \\
White & $0.20(0.20)$ \\
\hline
\end{tabular}

Another cultural indicator-"number of years in the US"-also related to students' perceptions. Analyses showed that students born in the US perceived less dissatisfied $(F=6.70)$ and admonishing $(F=4.36)$ behavior than students born outside the US. The variable explains about $1.5 \%$ of the total variance by itself. However, the number-of-years-in-the-US variable also interacts with the dominant language spoken at home: students born in the US and speaking predominantly Spanish at home perceive less admonishing $(F=4.26)$ and dissatisfied $(F=9.22)$ and more understanding $(F=6.18)$ behavior than other students born either in or outside the US Of the group born outside the US, students mainly speaking Spanish perceive more understanding and less admonishing behavior than non-US students speaking other languages, although this difference was not statistically significant. The percentages of variance explained by the interaction are similar to those explained by the number-of-years variable. The percentages of explained variance and the magnitude of the effects found hardly any changes between the 'raw' and 'adjusted' analyses.

Students' self-defined ethnic group membership related significantly to their perceptions of teacher admonishing behavior $(F=2.80)$, but only in the unadjusted case (see Table 5).

It seems, therefore, that White or Caucasian students perceive more admonishing behavior than their peers, while Hispanic-American students perceive less. About $3 \%$ of the variance in this category is explained by ethnic group membership. 
Table 6

Means and standard deviations (within brackets) for understanding by ethnic membership and language spoken at home

\begin{tabular}{|c|c|c|}
\hline Ethnicity & Language & Understanding (CS) \\
\hline \multirow{4}{*}{ African-American } & English & $0.73(0.17)$ \\
\hline & Spanish & Not available \\
\hline & Asian & Not available \\
\hline & Other & $0.63(0.15)$ \\
\hline \multirow[t]{4}{*}{ Asian-American } & English & $0.65(0.22)$ \\
\hline & Spanish & $0.85(0.08)$ \\
\hline & Asian & $0.70(0.24)$ \\
\hline & Other & Not available \\
\hline \multirow[t]{4}{*}{ Hispanic-American } & English & $0.66(0.24)$ \\
\hline & Spanish & $0.78(0.20)$ \\
\hline & Asian & Not available \\
\hline & Other & Not available \\
\hline \multirow[t]{4}{*}{ Caucasian/White } & English & $0.70(0.21)$ \\
\hline & Spanish & Not available \\
\hline & Asian & Not available \\
\hline & Other & Not available \\
\hline
\end{tabular}

Finally, an interaction effect was found between ethnic group membership and language spoken at home for understanding $(F=4.38)$. Asian-American students speaking Spanish at their homes perceived more understanding than other students, while Spanish speaking Hispanic-American students also perceived a considerable amount of understanding as compared to other students (see Table 6).

\section{Discussion}

Despite the higher-than-expected level of homogeneity in the sample, students' perceptions of interpersonal teacher behavior were nonetheless significantly related to their cultural background. Further, in those instances where significant effects occurred, the influence of culture on students' perceptions was surprisingly strong, accounting for $40-70 \%$ of the explained variance (though only $2-3 \%$ of the total variance). While the study's design was limited in several ways (see the last part of this section), these outcomes agree with previous research in demonstrating that a number of ethnic variables do affect students' perceptions of their teachers, even if students witness the same teacher behavior and if the effect of these ethnic variables is adjusted for other student characteristics. Since all participants were observing the same teacher behavior, the results support the assumption that culture affects students' values, norms and needs apart from any differences in treatment by the teacher. 
Students mainly speaking Spanish at home were found to rate teachers higher in terms of understanding and they also perceived less dissatisfaction and admonishing behavior (both independently and in interaction with the number of years of their stay in the US), while White students perceived more admonishing behavior. These findings concur with those of prior research in which Hispanic-American students viewed their teachers as more cooperative (den Brok et al., 2002; Levy et al., 1996, 2003). As was explained earlier, these findings may have been influenced by the importance attached to closeness and immediacy in collectivist societies such as those found in Latin America. The Hispanic-American students may have displayed a greater sensitivity to such behaviors, resulting in higher ratings (and correspondingly, lower ratings on opposite behavior).

Students born in the US perceived less dissatisfied behavior than students born outside the US, regardless of their ethnic background. This finding is contradictory to earlier research using the QTI, showing that students who have lived longer in the US have a more negative perception of their teacher than students who recently arrived (Levy et al., 2003; Evans \& Fisher, 2000). It remains unclear why this effect occurred, but the finding may be related to within-group diversity. The fact that rather broad categories such as 'Hispanic', 'Asian', and 'African' were used in the analyses has obviously obscured the fact that students within these groups originated from different countries. Further, perceptions are influenced by a lengthy set of variables including SES, war and political history, type of immigration, legal status, ethnic density and generation level, among many others. John Ogbu's identification of a caste system within immigrant populations is an excellent example of this complexity (Ogbu, 1978; Gibson and Ogbu, 1991).

Thus, the greater within-group diversity of the non-US born students compared to the US-born group may have influenced the result. Also, sample size of the present study was rather small compared to earlier studies. The finding that place of birth interacted significantly with students' languages spoken at home demonstrates that ethnicity and culture are extremely complex concepts with very subtle and implied effects on students' perceptions of their environment.

The percentages of (total) variance explained by the ethnic variables (about $3 \%$ per variable) may seem low, but are comparable to amounts of variance found in other studies that have also adjusted for covariates (e.g. den Brok et al., 2002; Levy et al., 2003). Moreover, earlier studies have shown that, while percentages of explained variance by ethnic variables may be marginal, absolute effects on students' perceptions may be considerable and often are similar or larger than effects of other student, class or teacher characteristics. Nevertheless, it cannot be ruled out that this outcome is also the result of design weaknesses, such as the small sample of students and teachers, the unsophisticated way of measuring culture and ethnicity and irregularities found in the circumplexity of the data.

As mentioned above, the sample of students in this study was socialized into mainstream American culture to a larger degree. Given the level of cultural similarity in the group it would have been reasonable to generate a null hypothesis prior to the study - in other words, expect no differences in perceptions between ethnic groups. This did not occur, however, there were clear differences between the cultures when 
all were presented with the same teacher behavior. As a result, we are left with an emerging impression of the power of culture. In short, while the students were much more culturally homogeneous than expected, culture still seemed to be a significant factor in students' perceptions. It is possible that despite the movement toward homogeneity caused by place of birth, years of residence in the US and home language, aspects of culture usually associated with countries in Asia and Latin America were still prevalent in the Asian-American and Hispanic-American participants. If accurate, this interpretation validates the importance of culture in teaching and learning.

While the study's limitations demand cautious interpretation of the results, the outcomes did seem to validate the importance of teachers' use of "culturally responsive" instructional techniques. Thus, continued emphasis on pre- and inservice development of constructivist methods such as inquiry learning, simulations, critical analysis, emphasis on students' funds of knowledge and authentic assessment are crucial. The literature on multicultural education is quite extensive, and there are many fine examples of teachers taking advantage of culture in the classroom.

The study suffered from several limitations. The first can be seen in its experimental nature. As a result of the design we were able to control for several factors that may have otherwise influenced the outcomes if the study had taken place in a school (such as influence of class composition and/or differences in teacher treatment). The disadvantage of the design, of course, is that the students were not actually taught by the teachers on the tapes and the content may have been different from their actual math class. Moreover, each student only observed four 15-min videotaped geometry lessons, whereas in a normal setting they would have had several lessons to base their perceptions on. Another limitation concerned the sample size of the study, which was small - only 78 students and 4 teachers participated. This makes it impossible to generalize the outcomes to a larger population and results in less stable estimations of the effect of cultural background. Last, questionnaires have limited potential when investigating the influence of a complex variable such as culture. Not only are students imposed with a framework (frequently by researchers who represent the dominant cultural group in the US), but also subtle and individual differences are not accounted for. This implies the use of more qualitative methods in future research, such as interviews with students or teachers and observations by researchers. This would not only allow for an analysis of (cross-cultural) differences in meaning attached to the study's variables (e.g. teacher leadership, cooperation, etc.), but would also assist in the search to explain the expected relationship between culture and students values, norms, needs and beliefs. Naturally, a quantitative study such as the one described cannot explain the perceptions of all individuals in a culture, due to the great amount of in-group diversity. Nevertheless, the insights provided by this study and similar ones may contribute to the knowledge base that helps teachers affirm diversity in their classroom, rather than ignore it.

With these limitations in mind, the study probably raised more questions than it answered regarding the specific role of culture in students' views of their teachers and their classes. Will studies with larger and more diverse samples show similar results? 
To what extent are the meanings attached to interpersonal concepts such as leadership, strictness, uncertainty, etc., different between the cultural groups of interest? Are the perceptions of the different cultural groups based on different observational cues in verbal and non-verbal behavior? Would the results have been different if students had been shown longer lesson fragments? Would similar effects have occurred if students rated teachers from other subjects? Finally, the finding that the QTI displayed differential outcomes with respect to validity deserves further study with other and larger samples. Despite these new issues raised, the study verified both the power and complexity of culture as an influence on cognition.

\section{Appendix A}

Items of the modified QTI are given in Table A1.

Table A1

Items of modified QTI

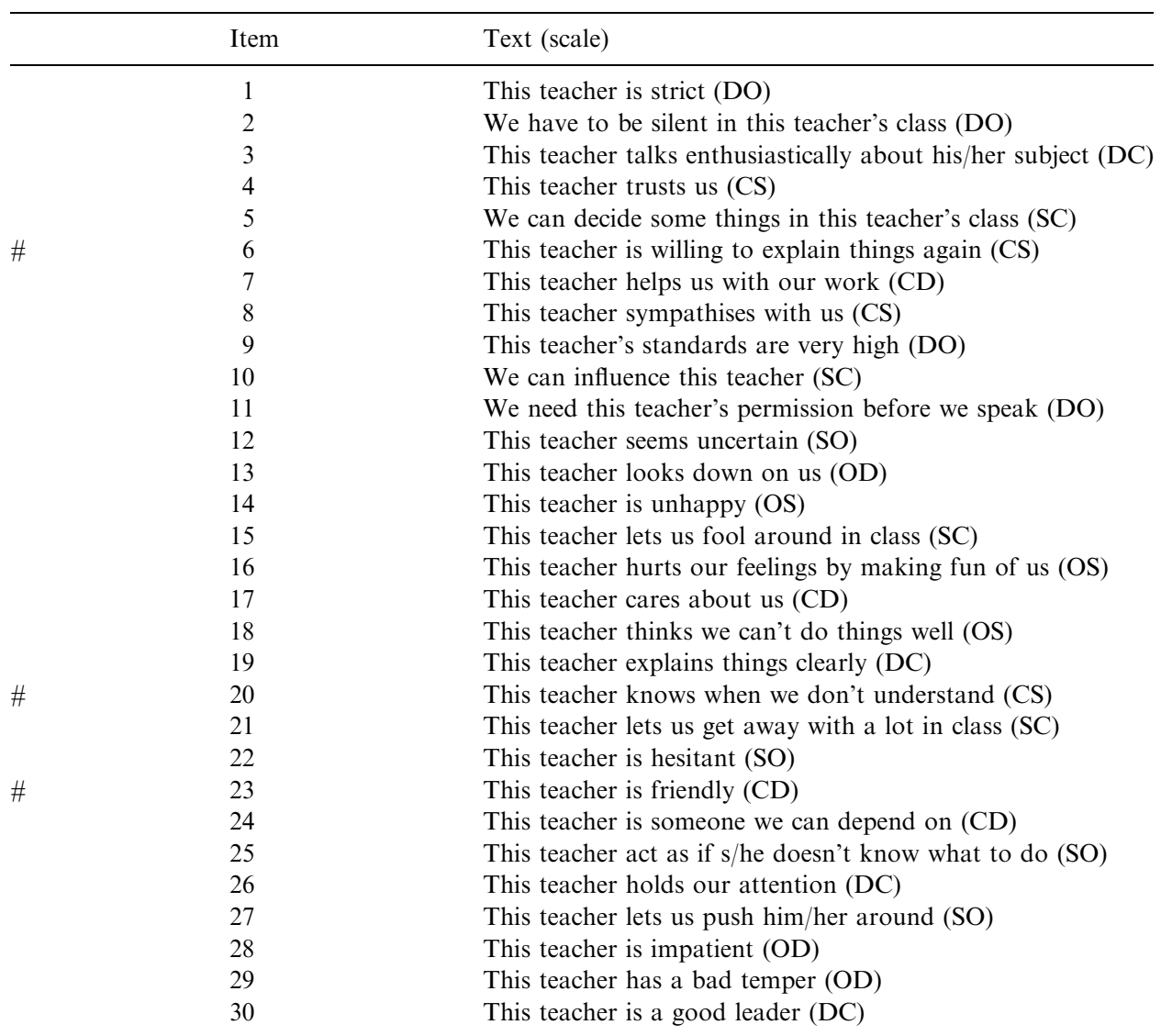


Table A1 (continued)

\begin{tabular}{ll}
\hline Item & Text (scale) \\
\hline 31 & This teacher seems dissatisfied (OS) \\
32 & This teacher is timid (SO) \\
33 & This teacher is patient (CS) \\
34 & This teacher is suspicious of us (OS) \\
35 & This teacher is rude (OD) \\
36 & This teacher's class is pleasant (CD) \\
37 & We are afraid of this teacher (DO) \\
38 & This teacher acts confidently (DC) \\
39 & This teacher is sarcastic (OD) \\
40 & This teacher is lenient (SC)
\end{tabular}

\#: removed item because of low internal reliability and validity.

\section{Appendix B}

Correlations between sector scores of each of the ethnic membership groups are given in Table B1.

Table B1

Correlations between sector score of each of the ethnic membership groups

\begin{tabular}{|c|c|c|c|c|c|c|c|c|}
\hline & DC & $\mathrm{CD}$ & $\mathrm{CS}$ & $\mathrm{SC}$ & $\mathrm{SO}$ & OS & OD & DO \\
\hline \multicolumn{9}{|c|}{ African-Americans $(N=76)$} \\
\hline DC & 1.00 & & & & & & & \\
\hline $\mathrm{CD}$ & 0.65 & 1.00 & & & & & & \\
\hline $\mathrm{CS}$ & 0.51 & 0.58 & 1.00 & & & & & \\
\hline $\mathrm{SC}$ & -0.49 & -0.27 & 0.10 & 1.00 & & & & \\
\hline SO & -0.68 & -0.43 & -0.33 & 0.62 & 1.00 & & & \\
\hline OS & -0.42 & -0.51 & -0.49 & 0.14 & 0.49 & 1.00 & & \\
\hline OD & -0.35 & -0.54 & -0.54 & -0.10 & 0.24 & 0.59 & 1.00 & \\
\hline DO & 0.40 & 0.24 & -0.14 & -0.65 & -0.36 & 0.04 & 0.36 & 1.0 \\
\hline
\end{tabular}

Asian-Americans $(N=64)$

DC $\quad 1.00$

$\begin{array}{lll}\text { CD } & 0.60 & 1.00\end{array}$

$\begin{array}{lll}\mathrm{CS} & 0.25 & 0.66\end{array}$

$\begin{array}{lll}\mathrm{SC} & -0.42 & 0.02\end{array}$

SO $\quad-0.80 \quad-0.31$

OS $\quad-0.22 \quad-0.48$

$-0.42$

1.00

$0.28 \quad 1.00$

$-0.01 \quad 0.56$

OD $\quad-0.08$

$-0.46$

$-0.10$

1.00

$-0.50 \quad-0.21$

$0.28 \quad 1.00$

DO $\quad 0.38$

$-0.03$

$-0.37$

$-0.61$

$-0.15$

0.51

1.00

$\begin{array}{lll}-0.48 & 0.21 & 0.47\end{array}$

Hispanic-Americans $(N=88)$

$\begin{array}{lrr}\text { DC } & 1.00 & \\ \text { CD } & 0.72 & 1.00 \\ \text { CS } & 0.69 & 0.83 \\ \text { SC } & -0.17 & 0.03 \\ \text { SO } & -0.76 & -0.52\end{array}$


Table B1 (continued)

\begin{tabular}{lrrlrrrrr}
\hline & DC & CD & CS & SC & SO & OS & OD & DO \\
\hline OS & -0.49 & -0.72 & -0.67 & -0.06 & 0.45 & 1.00 & & \\
OD & -0.34 & -0.65 & -0.59 & -0.10 & 0.28 & 0.80 & 1.00 & \\
DO & 0.36 & 0.01 & -0.04 & -0.59 & -0.42 & 0.04 & 0.36 & 1.00 \\
\multicolumn{2}{l}{ Caucasian } & or White & Americans $(N=84)$ & & & & & \\
DC & 1.00 & & & & & & & \\
CD & 0.65 & 1.00 & & & & & & \\
CS & 0.58 & 0.75 & 1.00 & & & & & \\
SC & -0.22 & 0.12 & 0.22 & 1.00 & & & \\
SO & -0.65 & -0.56 & -0.34 & 0.37 & 1.00 & & \\
OS & -0.48 & -0.71 & -0.71 & -0.27 & 0.41 & 1.00 & & \\
OD & -0.33 & -0.57 & -0.68 & -0.32 & 0.21 & 0.75 & 1.00 & \\
DO & 0.17 & -0.17 & -0.29 & -0.76 & -0.26 & 0.40 & 0.49 & 1.00 \\
\hline
\end{tabular}

\section{References}

Au, K. H., \& Kawakami, A. J. (1994). Cultural congruence in instruction. In E. R. Hollins, J. E. King, \& W. C. Hayman (Eds.), Teaching diverse populations: Formulating a knowledge base. Albany: State University of New York Press.

Brekelmans, M., van den Eeden, P., Terwel, J., \& Wubbels, Th. (1997). Student characteristics and learning environment interactions in mathematics and physics education: A resource perspective. International Journal of Educational Research, 27, 283-292.

Brekelmans, M., Wubbels, Th., \& Creton, H. (1990). A study of student perceptions of physics teacher behavior. Journal of Research in Science Teaching, 27, 335-350.

Brown, R. (1965). Social psychology. London: Collier-McMillan.

Casteel, C. A. (1996). Teacher-student interactions and race in integrated classrooms. Journal of Educational Research, 92(2), 115-121.

Chinese Culture Connection. (1987). Chinese values and the search for culture-free dimensions of culture. Journal of Cross-Cultural Psychology, 18, 143-164.

Cole, M., \& Scribner, S. (1974). Culture and thought: A psychological introduction. New York: Wiley.

den Brok, P. J. (2001). Teaching and student outcomes: A study on teachers' thoughts and actions from an interpersonal and a learning activities perspective. Utrecht: W.C.C.

den Brok, P. J., Levy, J., Rodriguez, R., \& Wubbels, Th. (2002). Perceptions of Asian-American and Hispanic-American teachers and their students on interpersonal communication style. Teaching and Teacher Education, 18, 447-467.

Dunkin, M. J., \& Biddle, B. J. (1974). The study of teaching. New York: Rinehart \& Winston.

Evans, H., \& Fisher, D. (2000). Cultural differences in students' perceptions of science teachers' interpersonal behaviour. Australian Science Teachers Journal, 46, 9-18.

Fisher, D., Rickards, T., Goh, S., \& Wong, A. (1997). Perceptions of interpersonal teacher behaviour in secondary science classes in Singapore and Australia. Journal of Applied Research in Education, 1, 2-11.

Foa, U. (1961). Convergences in the analysis of the structure of interpersonal behavior. Psychological Review, 68, 341-353.

Gaines, S. O., Panter, A. T., Lyde, M. D., Steers, W. N., Rusbult, C. E., Cox, C. L., \& Wexler, M. O. (1997). Evaluating the circumplexity of interpersonal traits and the manifestation of interpersonal traits in interpersonal trust. Journal of Personality and Social Psychology, 73, 610-623.

Gibson, M., \& Ogbu, J. (Eds.). (1991). Minority status and schooling : A comparative study of immigrant and involuntary minorities. New York: Garland.

Gordon, B. (1995). Knowledge construction, competing critical theories and education. In J. Banks, \& C. Banks (Eds.), Handbook of research on multicultural education (pp. 184-202). New York: Macmillan. 
Grossman, H. (1995). Teaching a diverse society. Boston: Allyn \& Bacon.

Hays, W. L. (1973). Statistics for the social sciences. London: Holt, Rhinehart \& Winston.

Hofstede, G. (1991). Cultures and organizations: Software of the mind. London: McGraw-Hill.

Hox, J. J. (1995). Applied multilevel analysis. Amsterdam: TT Publicaties.

Hubert, L., \& Arabie, P. (1987). Evaluating order hypotheses within proximity matrices. Psychological Bulletin, 102, 172-178.

Leary, T. (1957). An interpersonal diagnosis of personality. New York: Ronald Press Company.

Levy, J., den Brok, P., Wubbels, T., \& Brekelmans, M. (2003). Students' perceptions of interpersonal aspects of the learning environment. Learning Environments Research, 6(1), 1-31.

Levy, J., Wubbels, Th., \& Brekelmans, M. (1996). Cultural factors in students' and teachers' perceptions of the learning environment. Paper presented at the annual meeting of the American Educational Research Association, San Francisco.

Levy, J., Wubbels, T., Brekelmans, M., \& Morganfield, B. (1997). Language and cultural factors in students' perceptions of teacher communication style. International Journal of Intercultural Relationships, 21(1), 29-56.

Liberman, K. (1994). Asian student perspectives on American university instruction. International Journal of Intercultural Relations, 18, 173-192.

Lonner, W. J. (1980). The search for psychological universals. In H. C. triandis, \& W. W. Lambert (Eds.), Handbook of cross-cultural psychology, Vol. 1. (pp. 143-204). Boston: Allyn \& Bacon.

$\mathrm{Lu}$, S. (1997). Culture and compliance gaining in the classroom: A preliminary investigation of Chinese college teachers' use of behavior alteration techniques. Communication Education, 46, $10-28$.

Irvine, J. J. (1985). Teacher communication patterns as related to the race and sex of the student. Journal of Educational Research, 78, 338-345.

Irvine, J. J. (1986). Teacher-student interactions: Effects of student race, sex and grade level. Journal of Educational Psychology, 78, 14-21.

Matsuda, M. (1989). Working with Asian parents: Some communication strategies. Topics in Language Disorders, 9, 45-53.

McCroskey, J. C., Richmond, V. P., Sallinen, A., Fayer, J. M., \& Barraclough, R. A. (1995). A crosscultural and multi-behavioral analysis of the relationship between nonverbal immediacy and teacher evaluation. Communication Education, 44, 281-291.

Muthén, L. K., \& Muthén, B. O. (2001). MPLUS: Statistical analysis with latent variables; users guide. Los Angeles, CA: Stamodel.com.

Neuliep, J. W. (1995). A comparison of teacher immediacy in African-American and Euro-American college classrooms. Communication Education, 44, 267-280.

Nguyen, L. (1984). Indochinese cross-cultural adjustment and communication. Paper presented at the annual meeting of Teachers of English to Speakers of Other Languages, Houston: ERIC Document Reproduction Service No. ED 273068.

Nieto, S. (1996). Affirming diversity: The sociopolitical context of multicultural education. New York: Longman.

Nunally, J. C. (1967). Psychometric theory. New York: McGraw Hill.

Ogbu, J. (1978). Minority education and caste: The American system in cross-cultural perspective. New York: Academic Press.

Pinto, D. (2000). Intercultural communication: A three-step method for dealing with differences. Apeldoorn: Garant.

Samovar, L. A., \& Porter, R. E. (1995). Communication between cultures (2nd ed.). Belmont, CA: Wadsworth Publishing Company.

Sanders, J., Gass, R., Wiseman, R., \& Bruschke, J. (1992). Ethnic comparison and measurement of argumentativeness, verbal aggressiveness, and need for cognition. Communication Reports, 5, $50-56$.

Sanders, J. A., \& Wiseman, R. L. (1990). The effects of verbal and nonverbal teacher immediacy on perceived cognitive, affective and behavioral learning in the multicultural classroom. Communication Education, 39, 341-353. 
Segall, M.H., Dasen, P.R., Berry, J.W., \& Poortinga, Y.H. (Eds.). (1990). Human behavior in global perspective: An introduction to cross-cultural psychology. New York: Pergamon.

Simpson, A. W., \& Erickson, M. T. (1983). Teachers' verbal and nonverbal communication patterns as a function of teacher race, student gender and student race. American Educational Research Journal, 20, 183-198.

Stefani, L. A. (1997). The influence of culture on classroom communication. In: L. A. Samovar, \& R. E. Porter (Eds.), Intercultural communication: A reader (8th ed.). Belmont, CA: Wadsworth Publishing Company.

Sturtevant, W. C. (1964). Studies in ethnoscience. In J. W. Berry, \& P. R. Dasen (Eds.), Culture and cognition: readings in cross-cultural psychology (pp. 39-59). New York: Harper \& Row.

Tracey, T. J. (1994). An examination of complementarity of interpersonal behavior. Journal of Personality and Social Psychology, 67, 864-878.

Tracey, T. J. G. (1997). RANDALL: A microsoft FORTRAN program for a randomisation test of hypothesized order relations. Educational and Psychological Measurement, 57, 164-168.

Tracey, T. J., \& Schneider, P. L. (1995). An evaluation of the circumplex structure of the Checklist of Interpersonal Transactions and the Checklist of Psychotherapy Transactions. Journal of Counseling Psychology, 42, 496-507.

Witkin, H. A. (1967). A cognitive-style approach to cross-cultural research. International Journal of Psychology, 6, 4-87.

Wubbels, T., Créton, H. A, \& Hooymayers, H. P. (1985). Discipline problems of beginning teachers, interactional behavior mapped out. Paper presented at the American Educational Research Association annual meeting, Chicago. Abstracted in Resources in Education, 20(12), 153, ERIC document 260040.

Wubbels, T., Créton, H. A, \& Hooymayers, H. P. (1987). A school-based teacher induction programme. European Journal of Teacher Education, 10, 81-94.

Wubbels, T., \& Levy, J. (1991). A comparison of interpersonal behavior of Dutch and American teachers. International Journal of Intercultural Relationships, 15, 1-18. 